\title{
APRENDER EM GRUPO: EXPERIÊNCIA DE ESTUDANTES DE ENFERMAGEM E IMPLICAÇÕES PARA A FORMAÇÃO PROFISSIONAL
}

\section{Group learning: an experience of nursing students and implications for professional education}

\section{Aprender en grupo: experiencia de estudiantes de enfermería e implicaciones para la formación profesional}

\section{RESUMO}

0 objetivo desta pesquisa é compreender a experiência dos estudantes dos cursos de bacharelado e licenciatura em Enfermagem da Escola de Enfermagem de Ribeirão Preto/Universidade de São Paulo, no que se refere à aprendizagem em grupo, em disciplinas que possibilitam trabalhar em pequenos grupos de estudantes. Foram realizadas entrevistas não estruturadas com 19 alunos do segundo ano desses cursos, de abril a dezembro de 2007, e a análise qualitativa dos dados, pela qual se configuraram as categorias de codificação: Trabalhar em grupo facilita o aprendizado cognitivo e atitudinal; Trabalhar em grupo revela limites e requer mudanças; Trabalhar em grupo exige preparo e nova competência do professor; e Trabalhar em grupo possibilita um exercício para a prática profissional. A estratégia grupal contribui para o processo ensino-aprendizagem, promovendo mudanças na relação do estudante com o conhecimento, com o professor, com o colega e consigo mesmo.

Palavras-chave: Enfermagem. Ensino. Processos Grupais

\begin{abstract}
This research aims to understand the experience of students in the Bachelor and Teaching Diploma Nursing programs at the University of São Paulo in Ribeirão Preto College of Nursing (EERP/USP), Brazil, with respect to group learning, in subjects that permit working in small student groups. Non-structured interviews were held with 19 second-year students from the two programs, between April and December 2007. Qualitative data analysis was used, configuring codification categories: group work facilitates cognitive and attitudinal learning; group work reveals limits and demands changes; group work demands preparation and new competence from the teacher; group work permits an exercise for professional practice. Working in small groups makes it possible to exercise the professional practice. The group strategy contributes to the teaching-learning process, promoting changes in the student's relation with the knowledge, teachers, fellow students and themselves.
\end{abstract}

Key Words: Nursing. Learning. Group Processes

\section{Resumen}

La finalidad de esta investigación es comprehender la experiencia de los estudiantes de los cursos de bachillerato y licenciatura en enfermería, de la Escuela de Enfermería de Ribeirão Preto/ Universidad de São Paulo, con relación al aprendizaje en grupo, en asignaturas que posibilitan trabajar en pequeños grupos de estudiantes. Fueron realizadas entrevistas no estructuradas con 19 alumnos del segundo año de estos cursos, de abril a diciembre de 2007. Se llevó a cabo el análisis cualitativo de los datos, siendo configuradas categorías de codificación: trabajar en grupo facilita el aprendizaje cognitivo y actitudinal; trabajar en grupo marca límites y requiere cambios; trabajar en grupo exige preparación y nueva competencias del profesor; trabajar en grupo posibilita un ejercicio para la práctica profesional. La estrategia grupal contribuye al proceso enseñanza-aprendizaje, promoviendo cambios en la relación del estudiante con el conocimiento, con el profesor, con el colega y consigo mismo.

Palabras clave: Enfermería. Enseñanza. Procesos de Grupo

${ }^{1}$ Acadêmica de Enfermagem, Escola de Enfermagem da Universidade de São Paulo - Ribeirão Preto. Bolsista de Iniciação Científica. Brasil. E-mail: ro_gbarbato@yahoo.com.br, Enfermeira, Professora Doutora, Departamento de Enfermagem Geral e Especializada da Escola de Enfermagem de Ribeirão Preto/Universidade de São Paulo. Orientadora do Projeto. Brasil. E-mail: adricor@eerp.usp.br, ${ }^{3}$ Enfermeira, Professora Doutora, Departamento de Enfermagem Psiquiátrica e Ciências Humanas da Escola de Enfermagem de Ribeirão Preto/Universidade de São Paulo. Orientadora do Projeto. Brasil. E-mail: consouza@eerp.usp.br 


\section{INTRODUCÃO}

A partir da promulgação da Lei de Diretrizes e Bases da Educação Nacional, todos os cursos de graduação, incluindo os que compõem a área da saúde, vêm realizando movimentos de construção de projetos pedagógicos, tendo em vista as Diretrizes Curriculares Nacionais. ${ }^{1-2} \mathrm{~A}$ Escola de Enfermagem de Ribeirão Preto/Universidade de São Paulo (EERP/USP) está implementando, desde 2005, um novo currículo para o Curso de Bacharelado, e, em 2006, teve início o Curso de Licenciatura.

Um dos pontos essenciais apresentado nas Diretrizes Curriculares para os cursos de enfermagem se refere à formação do profissional voltada às necessidades de saúde no contexto do Sistema Único de Saúde (SUS): "a formação do enfermeiro deve atender às necessidades sociais da saúde, com ênfase no Sistema Único de Saúde, e assegurar a integralidade da atenção e a humanização do atendimento". 2-18

A construção da atenção integral supõe considerar, dentre outros aspectos, a concepção ampliada do processo saúdedoença, a gestão coletiva do trabalho, a capacidade de solucionar problemas cotidianos de modo crítico e contextualizado, tendo em vista a responsabilização e o compromisso ético-social com o usuário/cidadão. Esses aspectos exigem a construção de um trabalho interdisciplinar pautado em uma equipe que compartilhe saberes e práticas.

Do mesmo modo, ao incorporarmos a competência específica do campo de saber da educação, tendo em vista a formação do enfermeiro licenciado para a atuação na docência na educação profissional, e na promoção da saúde na educação básica, a preocupação com o trabalho em equipe permanece. A formação para a docência, na perspectiva da integralidade, também supõe um modo de conceber e operar o processo educativo que valorize o sujeito em suas múltiplas relações interpessoais e sociais, sendo que suas dimensões cognitivas, afetivas e psicomotoras integram-se no complexo fenômeno de aprender.

Assim, revela-se fundamental a discussão sobre 0 aprendizado para o trabalho grupal nos cursos de graduação em enfermagem, o que é reconhecido, inclusive, nas Diretrizes Curriculares anteriormente comentadas. Nessas Diretrizes, como comentam, há vários pontos sinalizadores essenciais do conhecimento acerca dos grupos. ${ }^{3}$ Aqui, destacamos, especificamente, os itens VI, VII e VIII desse documento que se referem à necessidade de definição de estratégias pedagógicas que articulem as dimensões do "saber, saber ser e saber conviver"; ao estímulo ao trabalho grupal, facilitador da discussão coletiva e das relações interpessoais; e à valorização das dimensões éticas e humanísticas pelo desenvolvimento de valores e atitudes orientados à cidadania e à solidariedade. ${ }^{2-}$ 30.

Cabem, assim, alguns questionamentos: a formação acadêmica vem facilitando o preparo do estudante para a atuação profissional em equipe? Como tem sido para 0 estudante de enfermagem vivenciar estratégias de atividades em grupo? As trocas de conhecimentos e experiências são potencializadas por estratégias de trabalho grupal? Os espaços de aprendizado grupal têm sido explorados para possibilitar a construção do trabalho em equipe/grupo, em seus aspectos cognitivos, afetivos e sociais?

0 objetivo deste estudo é compreender a experiência dos estudantes dos cursos de bacharelado e licenciatura em enfermagem da EERP/USP, no que se refere à aprendizagem em grupo, em disciplinas que possibilitam trabalhar em pequenos grupos de estudantes, operando na perspectiva da competência dialógica, da metodologia crítica e do currículo integrado, eixos do projeto pedagógico.

\section{REFERENCIAL TEÓRICO}

A prática do trabalho em grupo vem sendo cada vez mais exigida em nossa sociedade ainda marcada por individualismo, relações hierarquizadas e competitividade. 0 trabalho em grupo amplia a possibilidade de relações mais solidárias na medida em que as pessoas se reconhecem em suas semelhanças e diferenças, aprendendo a construir ideias e ações coletivamente. Esse tema - o trabalho em grupo - é estudado por diversos campos do saber, como a psicologia social, a psicanálise, a sociologia, dentre outros, havendo, pois, diversos enfoques teóricos da dinâmica de grupo.

0 trabalho em grupo favorece a interação entre os estudantes, incrementando a qualidade das aprendizagens e a aquisição de novos conhecimentos. Além disso, permite melhorar as habilidades sociais, possibilitando o diálogo, facilitando a comunicação e a inclusão de seus integrantes. Cabe ainda ressaltar que o trabalho em grupo faz com que os estudantes aprendam a ajudar-se mutuamente em suas aprendizagens, ou seja, de forma cooperativa, eles se tornam favoráveis às intenções e necessidades uns dos outros. ${ }^{4}$

Grupo operativo é "um conjunto de pessoas ligadas entre si por constantes de tempo e espaço e articuladas por sua mútua representação interna; propõe-se explícita e implicitamente uma tarefa, que constitui sua finalidade" $5: 169$.

A aprendizagem é uma leitura crítica da realidade envolvendo constante investigação na qual uma resposta já se constitui um disparador para nova pergunta. ${ }^{5}$ Aprender em grupo é preocupar-se não somente com o produto da aprendizagem, mas com o processo ensino-aprendizagem que gera mudanças nos sujeitos. "Aprendizagem, nessa perspectiva, é a capacidade de compreensão e de ação transformadora de uma realidade. Isso envolve mudanças e pressupõe que elas ocorram nas pessoas articuladas entre si e no contexto no qual as mesmas estão inseridas" $6: 30$.

A aprendizagem significa ir obtendo, apoiando-se no "velho", uma adaptação ao "novo". É isso que provoca resistências, pois, às vezes, diante do novo, os sujeitos sentem vontade de apegar-se ao velho que tampouco já satisfaz, ou seja, necessitam do novo, mas têm resistências para modificar. 
Nessa perspectiva de aprendizagem, os estudantes passam de receptores passivos para coautores, apropriando-se de suas potencialidades como seres humanos; ou seja, as capacidades dos estudantes e dos docentes têm que ser dinamizadas.?

Assim, faz-se relevante enfocar as experiências dos estudantes com a aprendizagem grupal, a partir de sua própria perspectiva.

\section{METODOLOGIA}

Trata-se de estudo descritivo-exploratório, de natureza qualitativa, considerando que o objeto de investigação em questão enfoca experiências humanas, valores e crenças que se constroem em determinado contexto, envolvendo dimensões objetivas e subjetivas próprias dos fenômenos sociais.

Após aprovação do projeto no Comitê de Ética em Pesquisa da EERP/USP, (Protocolo nº. 0779/2007) foram contatados e convidados a participar da pesquisa todos os estudantes que estavam cursando o segundo ano dos cursos de bacharelado e licenciatura, perfazendo um total de 130 alunos (80 do bacharelado e 50 da licenciatura), considerando que já viveram experiências do novo currículo, desenvolvidas em pequenos grupos, durante um ano.

Os interessados manifestaram-se para agendamento de entrevistas individuais, a serem realizadas fora do horário das atividades curriculares, nas próprias dependências da escola. Cabe destacar que a intenção era que a coleta de dados fosse iniciada em abril e finalizada em junho de 2007; todavia, impedimentos relacionados a horário, e mesmo desistência de alguns em participar, prolongaram essa fase da pesquisa até dezembro.

Para a realização de entrevista não estruturada, aquela que se processa quando, diante de um tema, o entrevistado pode abordá-lo de modo livre, ${ }^{8}$ foi utilizada uma questão norteadora a partir da qual os entrevistados expressaram suas ideias, sentimentos e experiências sobre a aprendizagem em grupo: "como tem sido para vocêa aprendizagem em pequenos grupos de estudantes?".

No momento da entrevista, o pesquisador novamente informou o entrevistado sobre os objetivos da pesquisa e o modo de conduzi-la, apresentando o Termo de Consentimento Livre e Esclarecido, garantindo o sigilo e a possibilidade de o participante retirar-se do estudo a qualquer momento se 0 desejasse, bem como obter informações sobre os seus resultados. Quando o entrevistado concordava, era utilizado o gravador para facilitar a coleta de dados fidedigna. Em uma única situação, houve recusa para tal e o entrevistador, imediatamente ao término da entrevista, fez o seu registro, buscando manter as falas, expressões, do entrevistado.

Como o estudo é de natureza qualitativa, não foi pré-fixado o número de sujeitos participantes. Àmedida que as entrevistas ocorreram, elas foram pré-analisadas, sendo utilizado o critério de saturação dos dados para finalização da coleta, o que se deu com a realização de 19 entrevistas (11B. e 8 L.).
Para a análise das entrevistas, foi realizada, inicialmente, a sua leitura exaustiva, sendo destacadas, em cada entrevista, frases significativas que vinham ao encontro dos objetivos da pesquisa. Após a análise de cada entrevista, elas foram articuladas umas às outras, sendo buscadas divergências e convergências dessas frases significativas, que foram então configuradas em categorias de codificação que constituem um meio de organizar os dados descritivos obtidos. ${ }^{9}$ Quando mencionadas no texto, as frases significativas estão identificadas: B (Bacharelado), L (Licenciatura), acompanhados do número do entrevistado.

Tais categorias de codificação englobaram ideias significativas comuns, ${ }^{9}$ a partir das quais foi possível compreender as experiências dos estudantes.

A compreensão dessas categorias, a partir de então, foi realizada pela aproximação inicial a ideias de autores específicos que vêm se dedicando ao estudo da constituição de grupos, suas dinâmicas e possibilidades como recurso para o processo ensino-aprendizagem.

\section{APRENDER EM GRUPO: EXPERIÊNCIAS DOS ESTUDANTES}

Da análise das falas das entrevistas, foram configuradas as seguintes categorias: Trabalhar em pequenos grupos facilita o aprendizado cognitivo e atitudinal; Limites do trabalho em grupo; Percepção do estudante em relação ao preparo do professor para coordenar grupos; Trabalhar em pequenos grupos possibilita o exercício para a prática profissional. Alguns pontos podem ser destacados em relação a cada uma dessas categorias.

Trabalhar em pequenos grupos facilita o aprendizado cognitivo e atitudinal

Em algumas situações, quando o estudante reconhece que o trabalho em grupo é facilitador da aprendizagem cognitiva, ele enfatiza sentir-se mais próximo do professor, que pode sanar suas dúvidas com mais efetividade do que em sala de aula, com grande número de pessoas.

... é bem melhor trabalhar em grupo menor, você consegue, você tem mais liberdade de perguntar, de tirar dúvidas, o professor também esta ali perto, é uma roda, então fica uma relação mais horizontal do professor como aluno... (B14).

... o grupo fica menor, então eu acho que a chance de aprender é melhor, você aprende mais, acaba tendo um vínculo maior com o professor,... eu tenho vergonha de perguntar numa sala de 50 ou 80 alunos; eu tenho uma dúvida, ás vezes eu acho que minha dúvida é idiota e fico acanhada de perguntar em uma sala grande...(L17). 
Por essas falas, nas entrelinhas, percebemos que alguns estudantes continuam com a ideia de que o professor é o único detentor do saber, não se percebendo como construtor do conhecimento nem reconhecendo que também pode aprender com os colegas. Cabe lembrar que até então, ao longo dos anos escolares, o aluno tem maior familiarização com o modelo tradicional de ensino, sendo o trabalho em pequenos grupos, por meio de metodologia problematizadora, algo novo para eles.

No modelo tradicional de ensino, a relação professor-aluno é vertical, sendo o professor o pólo que decide o modelo pedagógico, o conteúdo e a maneira da interação entre os alunos na sala de aula. Essas condutas o professor executa de acordo com objetivos externos, da escola ou da sociedade, tendo o aluno menos oportunidade de análise crítica e reflexão em relação ao assunto que naquele momento era significativo para seu aprendizado. ${ }^{10}$ No modelo tradicional, o aluno e o professor possuem uma relação em que há menor compartilhamento de informações entre eles, sendo o aluno apenas ouvinte do conhecimento transmitido pelo professor. Todavia, para outros estudantes, o trabalho grupal pode levar à reflexão e à troca de experiências, gerando maior autonomia.

... eu gosto de trabalhar em grupos, porque eu acho que a gente aprende bem, se relaciona melhor, você fica mais crítico, ..., você não esta pegando conhecimento pronto do professor, não tá te transmitindo conhecimento pronto, é o raciocínio dele, é você que lê, que desenvolve sua crítica, seu raciocínio e aprende. Aí o professor te fala se tem alguma coisa errada, se tem que observar mais ou menos. (L19).

Cabe ressaltar que não negamos que o professor é um sujeito detentor do saber e que cabe a ele fazer esclarecimentos, mas é diferente quando o faz na perspectiva de favorecer 0 desenvolvimento da atitude crítica e participativa do estudante e quando apenas se restringe ao caráter informativo.

A grande importância em um campo científico não é acumular conhecimento, mas sim utilizá-lo como instrumento para indagar e atuar sobre a realidade. Há diferença entre ter apenas o conhecimento acumulado e ter o conhecimento e saber utilizá-lo. 0 primeiro apenas aliena, já o segundo torna o ser humano e sua tarefa mais ricos. ${ }^{7}$

De modo muito significativo, aprender em grupo, para os estudantes, possibilita também o aprendizado vivencial, atitudinal: a convivência cotidiana com pessoas diversas vai gerando o desenvolvimento da escuta e do respeito pelo outro, fazendo com que o estudante repense sobre seus próprios valores.

... a gente aprende bastante "tecnicazinhas" de trabalhar em grupos, de ouvir mais, falar menos, você tem dois ouvidos para ouvir mais e uma boca para falar menos, eu fico com isso na cabeça, eu acho que é legal a gente começar a respeitar mais um pouco o outro (L17).

... acho a interação importante, você aprende a conviver com o outro, você aprende a ter mais tolerância, a ter mais paciência, a se policiar, a saber respeitar opiniões, a saber por sua opinião também...(B1).

"0 trabalho em grupo, em determinadas condições, incrementa a qualidade da aprendizagem e favorece a aquisição de conhecimento de alunos e alunas, por meio da interação entre eles..." 4:13. Por meio da relação grupal, uma maior interação entre os componentes do grupo torna a atividade mais dinâmica, mais participativa. Cada um contribui com sua individualidade, trocando experiências e conhecimentos, um contribuindo para o aprendizado do outro.

\section{Trabalhar em grupo revela limites e requer mudanças}

Durante as entrevistas, foram também destacados alguns limites da aprendizagem em pequenos grupos relacionados tanto ao aspecto cognitivo quanto ao atitudinal, pois trabalhar com o outro, aceitar as diferenças, aprender a escutar, aprender que o outro colega também pode ensinar, aprender a falar em grupo e compartilhar o seu conhecimento, é um processo de aprendizagem considerado relativamente novo em se tratando de um curso de graduação. Todo processo que se inicia é difícil; dessa forma, pode haver resistência entre os estudantes em relação à proposta de trabalho grupal.

Contrariamente a alguns alunos que reconhecem a aprendizagem em grupo como facilitadora da mudança atitudinal, outros afirmam que é justamente isso que os levam a não gostar da estratégia grupal, pois ela faz emergir seus próprios limites relacionais.

... É uma experiência bastante nova... eu não sei se eu gosto muito assim, eu prefiro mais o modelo da sala da aula para algumas matérias. É uma coisa que não tem como querer se esquivar, não tem como você querer fugir daquilo porque está de frente com o professor, todo mundo olhando para sua cara, não tem como você querer ficar mais quieto, não tem como você não prestar atenção, não tem como você não participar (L9).

... às vezes a gente encontra no estágio colegas... que não respeitam o seu tempo, então quando acontece isso dá para perder a paciência, as pessoas não têm a tolerância de entender, de repente, que uma não está bem hoje... (B1). 
Nas falas mencionadas acima, nas entrelinhas, os entrevistados apresentam uma visão idealizada da aprendizagem grupal, de que tem de estar sempre bem para trabalhar em grupo, ou seja, bem humorado, com paciência e participativo.

"Operar de modo cooperativo, por sua vez, não implica trabalhar sem conflitos. A presença deste é inevitável e universal"11:255. Trabalhar em grupo é um processo dinâmico, uma relação entre pessoas diferentes que, em determinados momentos, apresentam ações e sentimentos diferenciados, devendo haver construção de respeito do grupo em relação ao seu colega ou professor.

A aprendizagem grupal é um processo novo e exige mudanças, e mudanças também implicam aprendizado, o qual também se relaciona ao modo de ser de cada um. Processos de mudanças têm como consequência a ansiedade criada a partir do abandono de condutas já estereotipadas. A mudança gera resistência devido à ansiedade de perder o que já possui (identidade) e medo do desconhecido. Porém, essa resistência a mudanças implica um bloqueio da aprendizagem, de modo que a resistência quase sempre emerge em situações nas quais o homem se vê frente a algo novo $0^{12,8}$.

Um outro limite da aprendizagem grupal apontado pelos estudantes foi a diversidade existente, entre um grupo e outro, em relação aos conteúdos explorados durante as discussões. Eles estão inseridos em uma metodologia em que a sala de 80 alunos é dividida em vários grupos e as questões abordadas emergem da vivência de cada aluno nas imersões (atividade prática em cenário real), compartilhadas em seu subgrupo.

Acreditar que, em algum modelo de ensino, em uma sala de 80 ou em um grupo de 12 alunos, a aprendizagem seja homogênea, é ilusório, pois cada indivíduo possui um ritmo de aprendizagem diferente e uma determinada maneira de construir conhecimento. Na aprendizagem grupal, é inegável afirmar que não há diferença nos assuntos e questões abordadas em cada momento, já que os mesmos são norteados pela realidade da prática profissional cotidiana que é diversa e complexa.

O homem é quem constrói o mundo e edifica a sua realidade. Como construtor do mundo o homem é o único ser vivente que tem a capacidade de reflexão e comunicação, cabendo, então, a cada um, edificar sua realidade, isto é, seu olhar, sua verdade (relacionada à cultura, às crenças e experiências) para determinados assuntos e acontecimentos..$^{13}$ Obviamente, há conteúdos técnico-científicos, psicológicos e sociais que fundamentam o aprendizado profissional. Todavia, eles podem se tornar mais significativos se apreendidos e analisados a partir das experiências do cotidiano, à medida que os estudantes vão construindo a prática profissional nos serviços de saúde e educação.

Portanto, consideramos, pelas falas dos sujeitos, que ainda há maneiras diferentes dos estudantes (e professores) compreenderem o currículo por competência proposto. A preocupação com o conteúdo é importante, mas apenas conteúdos não são suficientes para que o estudante construa competência seja para o cuidado individual, coletivo ou gestão.

Cabe considerar que, talvez, nas entrelinhas, os estudantes tenham a compreensão de que, sendo garantidos determinados conteúdos, sua formação estará completa. Contudo, a graduação é a primeira etapa do aprendizado profissional, já que conteúdos cognitivos terão sempre que ser buscados à medida que a realidade exige. Do mesmo modo, atitudes e habilidades terão de ser revistas devido a experiências diferentes com pessoas diversas que o profissional encontrará ao longo da sua carreira. Ou seja, a graduação é apenas o início de uma aprendizagem contínua.

\section{Trabalhar em grupo exige preparo e nova competência do professor}

Como relatado pelos entrevistados, o professor pode contribuir para um melhor aprendizado do aluno. A atividade grupal permite uma relação horizontal do aluno com o professor, um maior contato entre eles e uma maior motivação do aluno em aprender, pelo fato de ser reconhecido dentro do grupo. Para trabalhar em grupo, o professor precisa ser flexível a mudanças, saber aceitar erros, ouvir, falar, sentir, pensar, agir, aceitar diferenças, problematizar e encontrar soluções com 0 grupo. Para alguns professores, todavia, o processo de mudança é difícil, o que é percebido e relatado por alguns estudantes:

... às vezes o professor não compreende que 0 aluno está passando por problemas pessoais... às vezes fala meio atravessado... essa tolerância também tem que vir do professor (B1).

... o professor não aceita críticas do grupo, mas ele sim chama atenção do aluno e a gente acha que quando está em grupo todos têm a liberdade de falar o que pensa... (B8).

Alguns estudantes enfatizaram que, além de atitudes, 0 professor que trabalha em pequenos grupos precisa desenvolver conhecimento e habilidades específicas para tal. Ainda existem alguns educadores que estão centrados em apenas transmitir conhecimento, sem conseguir perceber 0 funcionamento grupal e suas implicações para a aprendizagem. Nas falas das entrevistas B5 e L17, é mencionada a falta de conhecimento e habilidade de alguns professores para lidar com grupo.

... há professores que não estão ainda, não sei se é hábito, mas não estão... como posso dizer? Não compreenderam ainda o sentido do que é essa forma de estudo... (B5).

... eu acho que esses professores deveriam orientar mais a gente, direcionar melhor... às vezes eu acho que fica um pouco no achismo. Ah, eu acho que o grupo tem que buscar, ah eu acho que o grupo tem 
que refletir, eu acho, eu acho, eu acho que o grupo tem que pensar, o grupo tem que fazer isso... às vezes eu acho que a gente patina e não progride.(L17).

Para solucionar um problema é preciso questionar as origens das dificuldades, e a "chave" desse problema, a dificuldade do professor em coordenar grupo, pode ser o fato de não terem ensinado os professores como trabalhar em grupo. ${ }^{4}$

Para coordenar grupos, é necessário que o professor facilitador desenvolva competência, provindo dos seus estudos, leituras e experiências em grupo. Essa competência é tecida com atributos e funções denominadas: "Gostar e Acreditar em grupos" - o profissional que tem prazer no que faz torna a tarefa mais bem sucedida e não trabalha com desgaste pessoal, cabendo lembrar que gostar e acreditar em grupos não exclui sentir ansiedade, cansaço e descrença. "Coerência" - 0 coordenador como educador deve ser coerente para não resultar no educando sentimento de confusão e abalo de confiança básica. "Ética" - cabe ao educador respeitar valores e expectativas do outro, não impondo os seus. "Continência" - 0 professor deverá ter a habilidade de ser continente, saber conter as suas angústias próprias e necessidades dos outros, sempre com empatia para uma melhor relação afetiva, e desenvolver a comunicação valorizando o fato de ela não ser unicamente verbal. Assim, atitudes de paciência, ética e os atributos já citados anteriormente favorecem a "síntese e integração", isto é, a capacidade do coordenador de extrair a mensagem de cada componente do grupo, integrando em uma mensagem unificada, o que resulta em um processo de ensino competente. ${ }^{14: 42}$

Contrariamente a alguns entrevistados, outros ressaltam perceber um bom preparo por parte de alguns professores para coordenar grupo, isto é, competência para lidar com grupo, envolvendo flexibilidade para ensinar, aprender, escutar, aceitar e provocar críticas, falar, ouvir e propor discussões.

... eu vejo que eles têm bastante preparo para lidar, e bastante humildade no sentido de falar 'eu não sei', de aceitar críticas; nesse sentido, não tenho o que reclamar, sempre tive diálogo, sempre pude expor minha opinião... (B1).

... dependendo do professor, ele consegue levar, consegue atingir o objetivo da matéria, que é levantar hipóteses, você provocar no aluno aquela crítica, aquela reflexão...(B5).

0 professor é como se fosse um coordenador de um filme, ele deve garantir que a história tenha o final já previsto por parte de seu conhecimento; porém, o resultado e o processo de realização em que o filme irá acontecer dependerão de uma criação coletiva. ${ }^{15}$
Desta forma, é necessária competência para coordenar grupo e promover, assim, o aprendizado. Se o professor não possuir essa competência, como irá formar alunos no modelo proposto? A resistência à mudança de alguns professores pode refletir, inclusive, em um bloqueio do aprendizado para determinados alunos, como refere o entrevistado B5:

... alguns professores confrontam com você, falam: "não, o que você está falando eu não concordo... E não argumentam, e você às vezes fica quieta sem saber o que falar... (B5).

0 corpo docente precisa devolver continuamente 0 conhecimento cognitivo, atitudinal e habilidade para coordenar grupo. Uma parcela da aprendizagem de cada aluno depende do professor, que promove o aprendizado dos estudantes. E tal aprendizado articulado é fundamental para o desenvolvimento do aluno. 0 aluno, tendo uma formação que articule os elementos: conhecimentos, habilidade e atitudes, pode tornarse um profissional bem sucedido e socialmente engajado.

\section{Trabalhar em grupos possibilita um exercício para prática profissional}

0 projeto pedagógico, no contexto desta escola (EERP/ USP), tem como objetivo a formação de profissionais críticos e reflexivos, capacitados para lidar com a equipe, com o usuário e com o serviço de saúde. Para contribuir com a construção do cuidado integral, é fundamental o aprendizado do trabalho em grupo, já que somente na perspectiva interdisciplinar é que a equipe de saúde tem condições de cuidar do homem individual e coletivo em suas distintas dimensões. Desta forma, a aprendizagem em grupo, desde a graduação, pode permitir o desenvolvimento de atributos pelo aluno que contribuirão para a prática profissional.

0 aluno "aprende fazendo", e este é um modelo de aprendizagem que difere do clássico modelo teórico, proporcionando um melhor preparo para agir e refletir, por meio de experiências vividas. ${ }^{16: 14}$

A articulação da prática com a teoria, no modelo pedagógico atualmente proposto nesta escola, proporciona ao aluno o início de uma aprendizagem contínua que irá desenvolver ao longo da vida profissional. Durante as entrevistas, pelas falas dos estudantes, é nítido que a aprendizagem em pequenos grupos facilita a inserção na prática profissional:

... a gente com certeza vai lidar com equipe, com ideias diferentes, profissionais diferentes..., então acho que você vai começando desde a graduação a trabalhar com pessoas diferentes... (B14).

... saber respeitar os conhecimentos das pessoas, para mim esse foi o grande marco do currículo, é você ver a pessoa que você vai ensinar não como 
uma pessoa nula que está pela primeira vez ouvindo alguma coisa, ver que a vida dela traz conhecimento e você tem que respeitar isso, porque juntos, como conhecimento seu, o que você quer passar, mais o conhecimento da pessoa, você com certeza vai dar mais qualidade ao seu trabalho, tanto como professor quanto como enfermeiro...(L19).

Alguns alunos ainda ressaltam que esse modelo de ensinoaprendizagem proporciona também subsídios para o cuidado, pois além da equipe qualificar seu trabalho pela interação entre eles e respeito da singularidade de cada um, o aluno aprende também a respeitar o usuário do serviço, suas experiências, diferenças e seus direitos como cidadão:

... experiência tanto para lidar com pacientes, usuários, lidar mesmo com o ser humano em si, e colegas de trabalho. A gente sabe que vai encontrar vários tipos de pessoas ao longo do caminho profissional, mas o que vale mesmo é a experiência de vida, mesmo...(B1).

... como a gente aprende do contato que a gente vai ter com o paciente, de estar respeitando a individualidade dele, então, já trabalhando em grupo, a gente aprende a ser assim também... (B6).

Assim, a aprendizagem pela atividade grupal possibilita ao aluno um exercício para a prática profissional, pois ele aprende que opiniões, crenças e experiências são condições singulares construídas nas relações sociais, e que, para lidar com o outro, é preciso flexibilidade e respeito, saber escutar e dialogar, o que, para ser desenvolvido, necessita de contínuo aprendizado reflexivo.

\section{CONSIDERAÇÕES FINAIS}

A prática profissional do enfermeiro, seja na atenção, na gestão ou na docência, necessita do desenvolvimento de atributos relacionados à atuação em equipe, o que envolve, por exemplo, o autoconhecimento, a escuta, o diálogo, a convivência com a diversidade, a autenticidade, saberes e experiências específicos que permitem a compreensão do processo grupal (a dinâmica que se constrói quando as pessoas operam em conjunto/grupo) e as possibilidades de coordenação/ intervenção, no sentido de gerar situações de aprendizagem e transformação.

A estratégia de aprendizagem grupal é reconhecida como espaço que exercita a prática grupal, indo além do aprendizado apenas teórico sobre grupos, possibilitando a construção atitudinal com o outro. Todavia, limites do próprio estudante e do professor como coordenador precisam ser considerados. De qualquer modo, a estratégia grupal é mais uma possibilidade que permite transformar a prática pedagógica, trazendo contribuições ao processo ensino-aprendizagem, já que promove mudanças na relação do estudante com 0 conhecimento, com o professor, com o colega e consigo mesmo. Nesse contexto, a atuação do professor continua sendo fundamental, todavia, envolvendo um papel mais dinâmico, ativo, sintonizado com o processo grupal e a realidade concreta dos estudantes. Esse papel também requer aprendizado significativo. Assim, cabe ressaltar a necessidade de construir espaços de formação para o trabalho grupal para os professores universitários.

0 processo de ensino-aprendizagem em pequenos grupos possibilita também ao aluno um exercício para a prática profissional: eles aprendem a escutar, dialogar e compartilhar experiências, além de mudanças no seu modo de ser/atuar para realizar um trabalho em grupo/equipe criativo e crítico.

\section{REFERÊNCIAS}

1- Ministério da Educação (BR). Lei de Diretrizes e Bases da Educação Nacional. Brasília (DF); 1996.

2- Ministério da Educação (BR). Conselho Nacional de Educação. Parecer $n^{0} 1$, de 3 de abril de 2001. Estabelece normas para 0 funcionamento de cursos de pós-graduação.

3- Munari DB, Fernandes CNS. Coordenar grupos: reflexão à luz das diretrizes curriculares nacionais do curso de graduação em enfermagem. Rev Gaucha Enferm 2004 abr; 25(1): 26-32.

4- Bonals J. 0 trabalho em pequenos grupos na sala de aula. Porto Alegre (RS): Artmed; 2003.

5- Pichon-Rivièri E. 0 processo grupal. São Paulo (SP): Martins Fontes; 2000.

6- Gayotto MLC, Domingues I. Liderança: aprenda a mudar em grupo. Petrópolis (RJ): Vozes; 2000.

7 - Bleger J. Temas de psicologia: entrevistas e grupos. São Paulo (RS): Martins Fontes; 1993.

8- Minayo MCS. 0 desafio do conhecimento: pesquisa qualitativa em saúde. São Paulo (SP) Hucitec; 1999.

9- Bogdan R, Biklen S. Investigação qualitativa em educação: uma introdução à teoria e aos métodos. Lisboa (P0): Porto; 1994.

10- Mizukami NGM. Ensino: as abordagens do processo. São Paulo (SP): EPU; 1986.

11- Campos MA. 0 trabalho em equipe multiprofissional: uma reflexão crítica. Rev Bras Psiquiatr 1992 jul; 41 (6): 255-57.

12- Soares SM, Ferraz AF. Grupos operativos de aprendizagem nos service de saude: sistematização de fundamentos e metodologias. Esc Anna Nery Rev Enferm 2007 mar; 11(2): 52-57.

13- Duarte JF. 0 que é realidade. São Paulo (SP): Brasiliense; 1991.

14- Zimerman DE. Atributos desejáveis para um coordenador de grupo. In: Zimerman DE, Osório LC, et al. Como trabalhamos com grupo. Porto Alegre (SP): Artes Médicas; 1997. p. 41-47. 
Aprender em grupo: experiência de estudantes de Enfermagem

15- Gayotto MLC, organizador. Liderança II: aprenda a coordenar grupos. Petrópolis (RJ): Vozes; 2003.

16- Maranhão EA. A construção coletiva das diretrizes curriculares nacionais dos cursos de graduação da saúde: uma contribuição para o Sistema Único de Saúde, prefácio. In: Almeida.

M.,organizadora. Diretrizes curriculares nacionais para os cursos universitários da área da saúde. Londrina (PR): Rede Unida; 2003. 